\title{
Quantitative assessment of $S$. mutans and $C$. albicans in patients with Haas and Hyrax expanders
}

\author{
Matheus Melo Pithon', Rogério Lacerda dos Santos², Wagner Sales Alviano², \\ Antonio Carlos de Oliveira Ruellas ${ }^{4}$, Mônica Tirre de Souza Araújo ${ }^{4}$
}

Objective: To assess and compare the number of Streptococcus mutans and Candida albicans colonies in patients with Haas and Hyrax appliances before and after insertion.

Methods: The sample consisted of 84 patients requiring orthodontic treatment. For all patients a midpalatal suture expansion was indicated. Patients were randomly divided into Group HA, who used the Haas appliance $(n=42)$ and Group HY, who used the Hyrax appliance $(n=42)$. Initially and thirty days after appliance insertion all patients were submitted to saliva collections. The saliva was diluted followed by seeding in Mitis Salivarius and CHROMagar media, for growth of S. mutans and C. albicans respectively.

Results: Results showed statistically significant difference between groups HA and HY for Streptococcus mutans and Candida albicans ( $\mathrm{p}<0.05)$. Haas appliance promoted greater $S$. mutans and $C$. albicans proliferation when compared to Hyrax appliance.

Conclusion: The Haas appliance favored greater proliferation of $S$. mutans and C. albicans when compared with the Hyrax appliance. Insertion of the appliances resulted in greater buildup of microorganisms.

Keywords: Orthodontics. Orthodontic appliances. Streptococcus mutans. Candida albicans. Palatal expansion technique.

\footnotetext{
${ }^{1}$ Professor of Orthodontics, State University of the Southeast of Bahia. PhD in Orthodontics, Federal University of Rio de Janeiro (UFRJ). Diplomate of the Brazilian Board of Orthodontics and Dentofacial Orthopedics (BBO).

${ }^{2}$ Professor of Orthodontics, Campina Grande University. PhD Student in Orthodontics, UFRJ.

${ }^{3} \mathrm{PhD}$ in Orthodontics, UFRJ.

${ }^{4}$ Associate Professor of Orthodontics, UFRJ. Phd in Orthodontics, UFRJ.
}

How to cite this article: Pithon MM, Santos RL, Alviano WS, Ruellas ACO, Araújo MTS. Quantitative assessment of S. mutans and C. albicans in patients with Haas and Hyrax expanders. Dental Press J Orthod. 2012 May-June;17(3):21.el-6.

Submitted: November 10, 2008 - Revised and accepted: June 16, 2009

" The authors report no commercial, proprietary, or financial interest in the products or companies described in this article.

Contact address: Matheus Melo Pithon

Av. Otávio Santos, 395 - sala 705 - Vitória da Conquista/BA, Brazil

Zip code: 45.020-750 - E-mail: matheuspithon@gmail.com 


\section{INTRODUCTION}

The majority of devices used for orthodontic treatment encumber patient's adequate dental hygiene, thus altering the quantity and composition of the oral microbiota. Several studies have reported the direct association between the presence of orthodontic bands, ${ }^{19,25,39}$ brackets $^{13,19,32,43}$ and other appliance ${ }^{5,29}$ with greater biofilm accumulation, and consequently, a higher incidence of enamel demineralization and even carious lesions. ${ }^{31,34,36}$

The process of biofilm formation begins immediately after insertion of orthodontic appliances, with fixation of the primary colonizing bacteria, in general streptococcus, and progresses, culminating in the appearance of strict anaerobic gram negative bacilli. ${ }^{6}$ The streptococci are associated with pathologic processes that range from dental caries in patients with poor oral hygiene and a diet rich in fermentable sugars, to bacteremias, when orthodontic bands are removed. The strict anaerobic microbiota is particularly associated with periodontal disease., ${ }^{6,32,29}$

One of the fixed appliances frequently used in children and adolescents in orthodontic clinics is the palatal expander, used to correct skeletal posterior crossbites or just for maxillary arch expansion in cases of maxillary atresia. In the literature, there is an infinite number of appliances used for this purpose, ${ }^{4,9,10,12,23,26,37}$ however, those most frequently and widely used are the Haas appliance, recommended by $\mathrm{Hass}^{22}$ in 1961 and the Hyrax appliance..$^{8,18}$

The Haas appliance has an acrylic resin component which remains in intimate contact with the palate for a minimum period of approximately four months. Clinically, over appliance removal, a thick biofilm buildup is noted under the acrylic component.

Aiming at the achievement of favorable results,such as those achieved with the Haas type appliance, but without biofilm accumulation, Biederman ${ }^{8}$ developed the Hyrax appliance, which has the same indications as the Haas appliance, however, supported only by teeth, without the acrylic component. Due to the absence of the acrylic support, hypothetically the Hyrax appliance would promote less biofilm accumulation, and consequently, less $S$. mutans and $C$. albicans proliferation. In the attempt of confirming this hypothesis, the aim of the present study was to make a quanti- tative assessment of the number of $C$. albicans and $S$. mutans colonies before and after these appliances are inserted.

\section{MATERIALS AND METHODS}

This study was conducted in compliance with the demands of the Research Ethics Committee of the Federal University of Rio de Janeiro - UFRJ. The volunteers were able to participate in the study after explanations with respect to the research and the express agreement of their guardians, which was obtained by signature of the terms of free and informed consent.

The sample consisted of a total of eighty-four patients yet to receive orthodontic treatment at the clinic of the Master's Course in Dentistry at the Federal University of Rio de Janeiro. The patients were in the age-range between 13 years and 04 months and 15 years and 9 months, 42 being girls and 42 boys. The patients were selected according to the need for orthodontic treatment associated with maxillary expansion in cases of unilateral or bilateral crossbite and cases of atresic maxilla without the occurrence of crossbite.

\section{Appliances used}

The expander appliances were fabricated by the same operator, and differed in design (related to the anatomy of the patient's palatine region), and the quantity of activations (related to the treatment plan) (Figs 1 and 2).

\section{Inserting the appliances}

Before inserting the appliances, patients were instructed with regard to correct bacterial plaque control.

After the instructions had been given, the expanders were cemented to the patients' maxillary first premolars and first molars with glass ionomer cement (Vidrion C, Juiz de Fora, Brazil). The person who accompanied the patient was then instructed about how to activate the appliance, which varied according to each patient's individual requirements.

\section{Groups evaluated}

Two groups were formed for evaluation:

» Group Ha: Which used the Haas appliance $(\mathrm{n}=42)$.

» Group Hy: Which used the Hyrax appliance $(\mathrm{n}=42)$. 


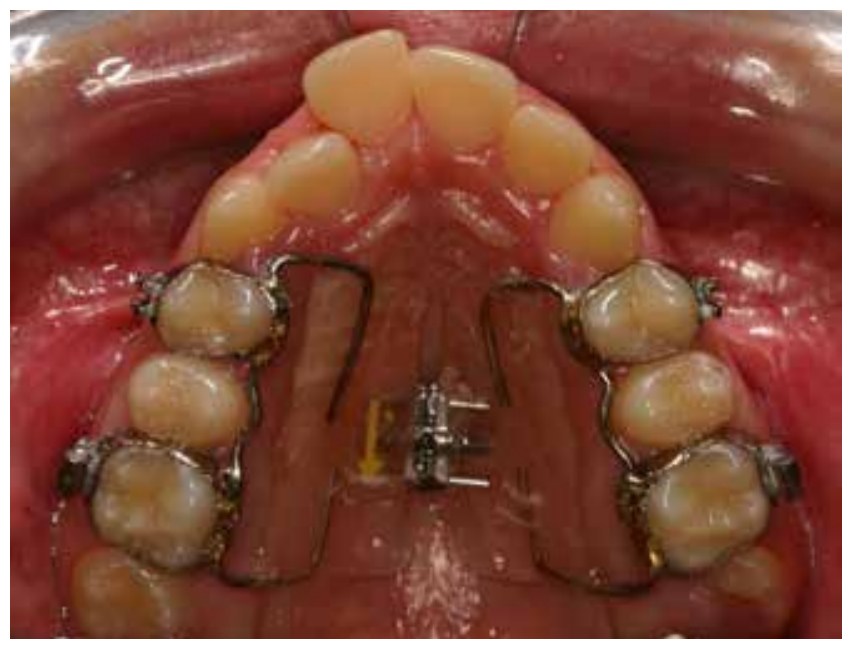

Figure 1 - Patient from group Ha, using Haas appliance.

\section{Saliva collection}

Prior to appliance insertion and 30 days postinsertion saliva was collected. Unstimulated saliva collection was carried-out using sterilized plastic receptacles with lids. Patients were instructed to expel saliva into the receptacle until a volume of approximately $3 \mathrm{ml}$ was collected. The flask containing saliva was transported in a thermal receptacle with ice, and was processed within 2 hours after collection. The same saliva sample was used for isolating both C. albicans and $S$. mutans.

\section{Estimate of $S$. mutans in saliva}

For the isolation of $S$. mutans, dilutions $\left(10^{-1}\right.$ and $\left.10^{-2}\right)$ of the saliva samples were performed in peptonized water, homogenized in a magnetic agitator and $0.1 \mathrm{ml}$ of each dilution was seeded in Agar Mitis Salivarius with bacitracin $(30 \mathrm{mg} / \mathrm{ml}$ of medium) and potassium tellurite $(0.00005 \%)$, and incubated at $37{ }^{\circ} \mathrm{C}$ for 48 hours under a microaerophilic atmosphere, with the use of a Gaspack jar.

After incubation, estimated colony counts of streptococcus of the mutans group were performed by multiplying the number of colonies in a standardized area of $1 \mathrm{~cm}^{2}$ by the respective dilution factor.

\section{Estimate of yeasts of the genus Candida albicans in saliva}

For the isolation of $C$. albicans, the saliva samples were diluted to $10^{-1}$ in Sabouraud broth, and homogenized in a magnetic agitator. From this dilution, $0.1 \mathrm{ml}$

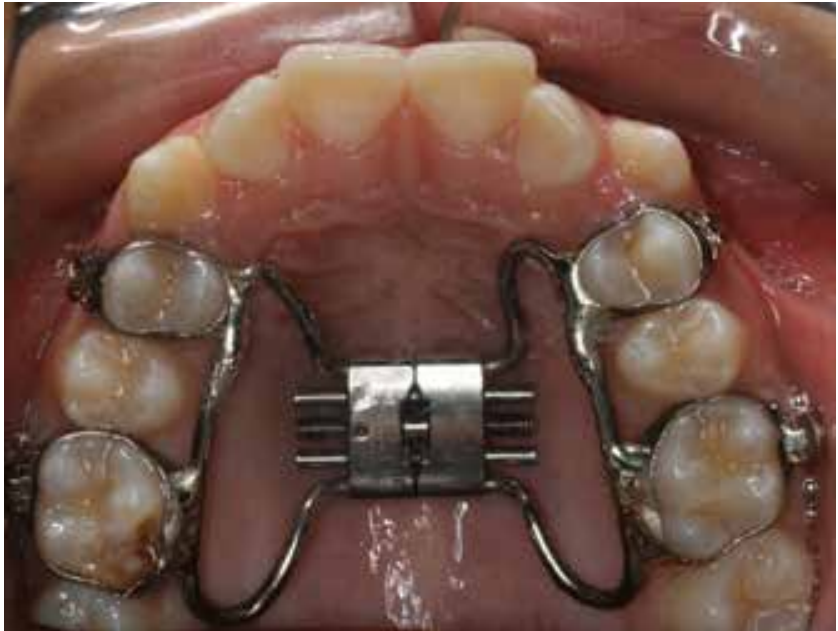

Figure 2 - Patient from group Hy, using Hyrax appliance.

of each sample was seeded in Agar Sabouraud Dextrose, and incubated at $300{ }^{\circ} \mathrm{C}$ for a 48 hours to 7 days period. The colonies developed in the culture medium were identified by their macroscopic and microscopic morphological characteristics.

An estimated count of the number of Colony Forming Units (CFU), was performed by multiplying the number of colonies by the dilution factor.

\section{Statistical treatment}

Statistical analysis were performed with the aid of SPSS 13.0 software (SPSS Inc., Chicago, Illinois, USA). The number of colony forming units (CFU) in each group was submitted to the analysis of variance (ANOVA) to determine whether there were statistical differences between the groups, and afterward to the Tukey test.

\section{RESULTS}

The results showed that proliferation of $S$. mutans (Fig 3) and C. albicans (Fig 4) was significantly higher inpatients with Haas appliance when compared with those that underwent expansion with Hyrax appliance. There was statistically significant difference between Groups Ha and Hy for S. mutans $(\mathrm{p}=0.001)$ and $C$. albicans $(\mathrm{p}=0.000)$. Patients with Haas appliance displayed higher variations in colony counts for S. mutans and C. albicans.

After insertion of the appliances there was a significant increase in the number of $S$. mutans and $C$. albicans both in the group that used Haas appliance as in the one that used Hyrax appliance $(p<0.005)$. 


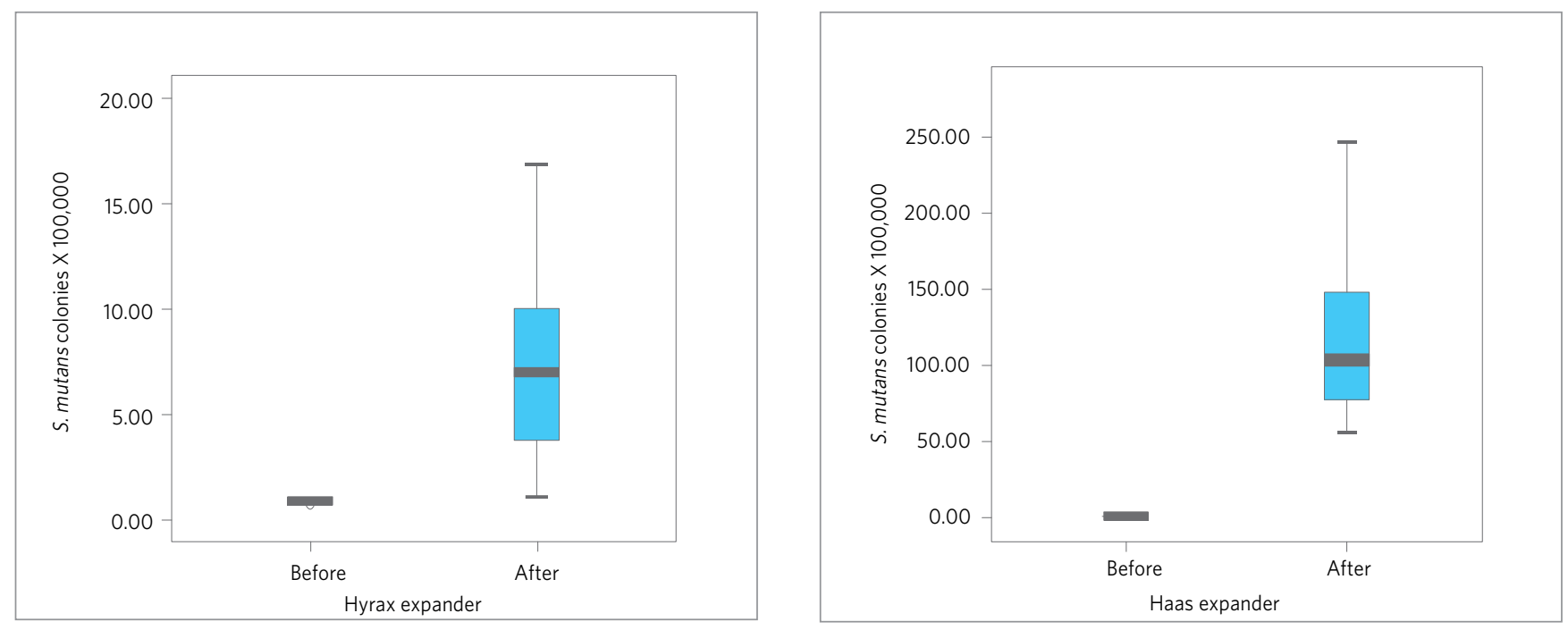

Figure 3 - S. mutans colonies count (CFU / ml) collected from patients with Hyrax and Haas expanders.
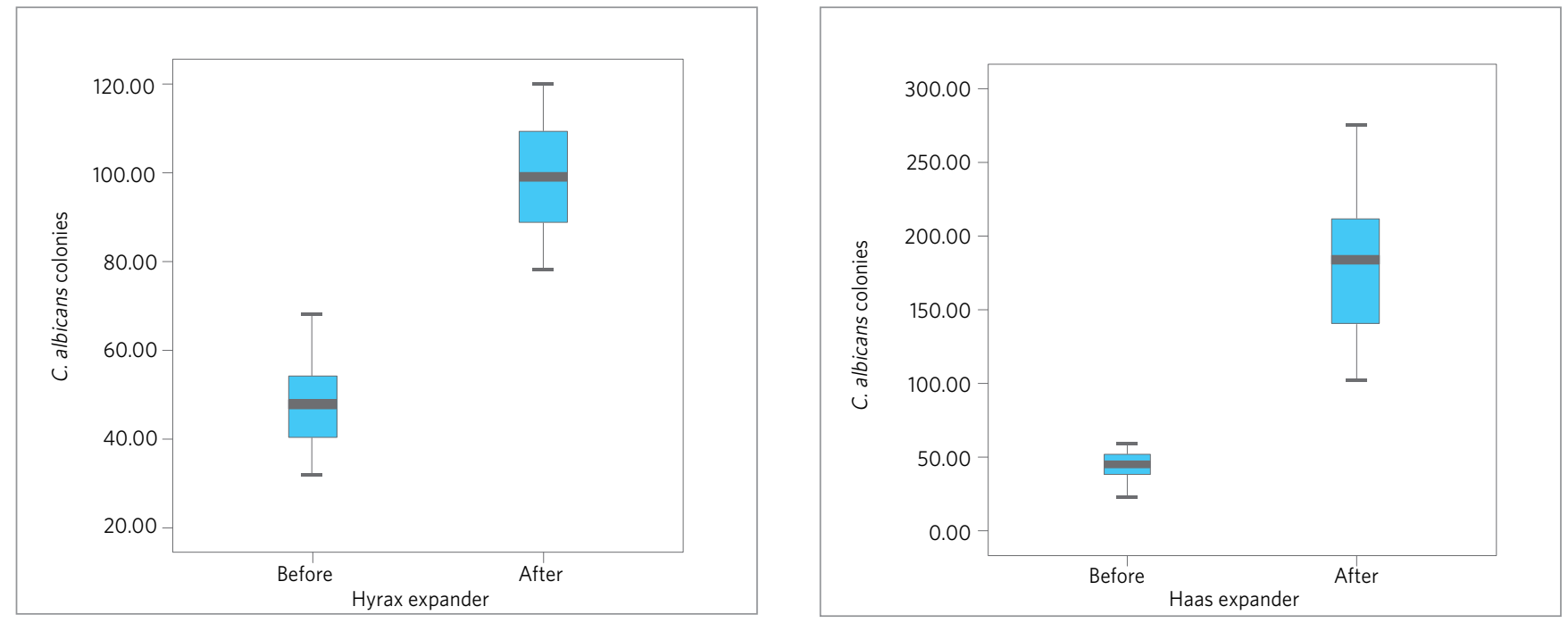

Figure 4 - C. albicans colonies count (CFU / ml) collected from patients with Hyrax and Haas expanders.

\section{DISCUSSION}

The oral environment offers ideal conditions for colonization of its anatomic parts by a very complex microbiota that coexists in equilibrium with the host. ${ }^{15}$ However, when changes in the oral environment occur, the microbiota also changes, resulting in imbalance, with the possibility of diseases development. ${ }^{30}$

Orthodontic treatment, particularly by means of fixed appliances, predisposes to specific alterations in the oral environment, ${ }^{3}$ including $\mathrm{pH}$ reduction, increase in dental biofilm accumulation ${ }^{33}$ and elevation in the salivary levels of microorganisms. ${ }^{27}$
Considering that orthodontic appliances are composed of a variety of solid and elastic materials, ${ }^{42}$ after they are inserted into the oral cavity, specific salivary proteins will adsorb on their different surfaces, ${ }^{2,42}$ conditioning them and playing an important role in bacterial adhesion. In addition, the irregular surfaces of brackets, bands, wires and other accessories function as bacterial biofilm retention areas, ${ }^{2,27}$ encumber dental hygiene ${ }^{35}$ and limit the occurrence of mechanical self-cleaning produced by saliva and musculature movement. ${ }^{38}$

These factors favor a drop in the $\mathrm{pH}$ of dental biofilm in the presence of fermentable carbohydrates, 
accelerating the accumulation and maturation of cariogenic biofilm, fundamentally composed of streptococcus of the mutans group, which are aciduric and acidogenic microorganisms, ${ }^{19}$ considered the primary etiologic agents of dental caries., ${ }^{7,28}$

Although the oral cavity presents countless species of microorganism $s^{15}$, this study assessed the presence of streptococcus of the mutans group, as they are considered the primary etiologic agents of dental caries ${ }^{15}$ and because they are the microorganisms that most commonly contaminate orthodontic appliances; ${ }^{1,41}$ and Candida albicans, which are frequent microorganisms in the oral cavity, and may or may not be associated with pathologies.

For microbiological evaluation the dilution technique was employed, in which the specimens were submitted to mechanical agitation for desorption of the microorganisms, and the resultant suspensions were diluted and seeded in a solid culture medium. Different solid culture media have been used for detecting streptococcus of the mutans group, such as Agar $\mathrm{SB}_{20}{ }^{11}{ }^{11} \mathrm{MS}-\mathrm{MUTV}^{44}$ and TYCSB,${ }^{45}$ among others. In this study, Agar $\mathrm{MSB}^{17}$ was used, as occurs in various studies..$^{20,21,24,46,47}$ For candida the Agar Sabouraud Dextrose medium was used, one of the most frequently used media when studying $C$. albicans. ${ }^{14,16,40}$

In this study the proliferation of $S$. mutans and $C$. albicans was significantly higher in patients that underwent expansion with Haas appliance when compared to the Hyrax appliance.

The Haas expander is a dental-mucous-supported appliance which, in addition to orthodontic bands and an expander screw, has an acrylic structure that differentiates it from the Hyrax appliance.
The acrylic structure may influence on the proliferation of microorganisms, when it acts as a food deposit, depending on its size and smoothness. In this study it was observed that patients with Haas expander presented the greatest variations in colony counts for $S$. mutans and $C$. albicans. In addition to the acrylic structure, factors such as the difficulty in dental hygiene, palate depth, mastery of tooth brushing techniques and frequency of brushing performed by the patient may have influenced the proliferation of $S$. mutans e C. albicans.

To verify to what extent these appliances would favor bacterial accumulation, saliva was evaluated before and 30 days after insertion of the appliances. A significant increase in microorganisms count could be noted both in the individuals who were using Haas and Hyrax appliances $(\mathrm{p}<0.005)$.

It should also be taken into consideration the lower standard deviation found in the first collection when compared to the second one. This fact could be justified by the appliances design, which in spite of having been fabricated by the same operator, had particular characteristics for each individual, also by the individual response of each host to the new intraoral device, and by personal dental hygiene.

\section{CONCLUSIONS}

By conducting this study, it could be concluded that:

» the insertion of Haas and Hyrax expanders favors greater accumulation of microorganisms ( $S$. mutans and $C$. albicans).

» The Haas expander favored greater proliferation of $S$. mutans and $C$. albicans when compared to the Hyrax expander. 


\section{REFERENCES}

1. Ahn SJ, Lim BS, Lee SJ. Prevalence of cariogenic streptococci on incisor brackets detected by polymerase chain reaction. Am J Orthod Dentofacial Orthop. 2007 Jun;131(6):736-41.

2. Ahn SJ, Lim BS, Lee YK, Nahm DS. Quantitative determination of adhesion patterns of cariogenic streptococci to various orthodontic adhesives. Angle Orthod. 2006 Sep;76(5):869-75

3. Anhoury P, Nathanson D, Hughes CV, Socransky S, Feres M, Chou LL. Microbial profile on metallic and ceramic bracket materials. Angle Orthod. 2002 Aug;72(4):338-43.

4. Arman A, Ufuk Toygar T, Abuhijleh E. Evaluation of maxillary protraction and fixed appliance therapy in Class III patients. Eur J Orthod. 2006 Aug;28(4):383-92.

5. Auschill TM, Hein N, Hellwig E, Follo M, Sculean A, Arweiler NB. Effect of two antimicrobial agents on early in situ biofilm formation. J Clin Periodontol. 2005 Feb;32(2):147-52.

6. Balenseifen JW, Madonia JV. Study of dental plaque in orthodontic patients. J Dent Res. 1970 Mar-Apr;49(2):320-4.

7. Berkowitz RJ. Causes, treatment and prevention of early childhood caries: a microbiologic perspective. J Can Dent Assoc. 2003 May;69(5):304-7.

8. Biederman W. A hygienic appliance for rapid expansion. JPO - J Pract Orthod. 1968 Feb;2(2):67-70

9. Buccheri A, Dilella G, Stella R. Rapid palatal expansion and pharyngeal space. Cephalometric evaluation. Prog Orthod. 2004;5(2):160-71.

10. Chung $\mathrm{CH}$, Font B. Skeletal and dental changes in the sagittal, vertical, and transverse dimensions after rapid palatal expansion. Am J Orthod Dentofacial Orthop. 2004 Nov;126(5):569-75.

11. Davey AL, Rogers AH. Multiple types of the bacterium Streptococcus mutans in the human mouth and their intra-family transmission. Arch Oral Biol. 1984;29(6):453-60.

12. De Coster T. Orthopedic expansion of the maxilla. Orthod Fr. 2006 Jun;77(2):253-64.

13. Diamanti-Kipioti A, Gusberti FA, Lang NP. Clinical and microbiological effects of fixed orthodontic appliances. J Clin Periodontol. 1987 Jul;14(6):326-33.

14. Farley JE, Stamper PD, Ross T, Cai M, Speser S, Carroll KC. Comparison of the BD GeneOhm methicillin-resistant Staphylococcus aureus (MRSA) PCR assay to culture by use of BBL CHROMagar MRSA for detection of MRSA in nasal surveillance cultures from an at-risk community population. J Clin Microbiol. 2008 Feb;46(2):743-6.

15. Fejerskov OE, Kidd E. Cárie dentária. A doença e seu tratamento clínico. São Paulo (SP): Ed. Santos; 2005

16. Furlaneto-Maia L, Specian AF, Bizerra FC, de Oliveira MT, Furlaneto MC. In vitro evaluation of putative virulence attributes of oral isolates of Candida spp. obtained from elderly healthy individuals. Mycopathologia. 2008 Oct;166(4):209-17.

17. Gold OG, Jordan HV, Van Houte J. A selective medium for Streptococcus mutans. Arch Oral Biol. 1973 Nov;18(11):1357-64.

18. Goldenberg DC, Goldenberg FC, Alonso N, Gebrin ES, Amaral TS, Scanavini MA, et al. Hyrax appliance opening and pattern of skeletal maxillary expansion after surgically assisted rapid palatal expansion: a computed tomography evaluation. Oral Surg Oral Med Oral Pathol Oral Radiol Endod. 2008 Dec;106(6):812-9.

19. Gorelick L, Geiger AM, Gwinnett AJ. Incidence of white spot formation after bonding and banding. Am J Orthod. 1982 Feb;81(2):93-8.

20. Groppo FC, Ramacciato JC, Simões RP, Flório FM, Sartoratto A. Antimicrobia activity of garlic, tea tree oil, and chlorhexidine against oral microorganisms. Int Dent J. 2002 Dec;52(6):433-7.

21. Gudiño S, Rojas N, Castro C, Rodríguez M, Vega M, López LM. Colonization of mutans streptococci in Costa Rican children from a high-risk population. J Dent Child (Chic). 2007 Jan-Apr;74(1):36-40.

22. Haas AJ. Rapid expansion of the maxillary dental arch and nasal cavity by opening the mid-palatal suture. Angle Orthod. 1961;31:73-90.

23. Hayes JL. Rapid maxillary expansion. Am J Orthod Dentofacial Orthop. 2006 Oct;130(4):432-3; author reply 2006;433-4.

24. Hildebrandt $\mathrm{GH}$, Bretz WA. Comparison of culture media and chairside assays fo enumerating mutans streptococci. J Appl Microbiol. 2006 Jun;100(6):1339-47.

25. Huser MC, Baehni PC, Lang R. Effects of orthodontic bands on microbiologic and clinical parameters. Am J Orthod Dentofacial Orthop. 1990 Mar;97(3):213-8.
26. Kiliç N, Oktay H. Effects of rapid maxillary expansion on nasal breathing and some naso-respiratory and breathing problems in growing children: A literature review Int J Pediatr Otorhinolaryngol. 2008 Nov;72(11):1595-601.

27. Leung NM, Chen R, Rudney JD. Oral bacteria in plaque and invading buccal cells of young orthodontic patients. Am J Orthod Dentofacial Orthop. 2006 Dec;130(6):698.e11-8.

28. Loesche WJ. Role of Streptococcus mutans in human dental decay. Microbiol Rev. 1986 Dec;50(4):353-80.

29. MacPherson LM, MacFarlane TW, Stephen KW. An intra-oral appliance study of the plaque microflora associated with early enamel demineralization. J Dent Res. 1990 Nov;69(11):1712-6

30. Marsh PD. Dental plaque as a biofilm and a microbial community - implications for health and disease. BMC Oral Health. 2006 Jun 15;6 Suppl 1:S14.

31. Maserejian NN, Trachtenberg F, Hayes C, Tavares M. Oral health disparities in children of immigrants: dental caries experience at enrollment and during follow-up in the New England childrens amalgam trial. J Public Health Dent. 2008 Winter;68(1):14-21.

32. Mattingly JA, Sauer GJ, Yancey JM, Arnold RR. Enhancement of Streptococcus mutans colonization by direct bonded orthodontic appliances. J Dent Res. 1983 Dec;62(12):1209-11.

33. Naranjo AA, Triviño ML, Jaramillo A, Betancourth M, Botero JE. Changes in the subgingival microbiota and periodontal parameters before and 3 months after bracket placement. Am J Orthod Dentofacial Orthop. 2006 Sep;130(3):275.e17-22.

34. Oliveira LB, Sheiham A, Bönecker M. Exploring the association of dental caries with social factors and nutritional status in Brazilian preschool children. Eur J Oral Sci. 2008 Feb;116(1):37-43

35. Olympio KPK, Bastos JRM, Henriques JFC, Cardoso VES, Silva PA, Bardal PAP, et al. Caries y enfermidad periodontal causadas por tratamiento ortodóntico en ausencia de un programa educativo-perventivo. Rev Odon Dominicana. 2003;9:31-7

36. Percy MS. Oral health of adolescents--its more than dental caries. MCN Am J Matern Child Nurs. 2008 Jan-Feb;33(1):26-31.

37. Ren Y. Rapid maxillary expansion treatment could produce long-term dental arch changes. Evid Based Dent. 2005;6(4):93-4.

38. Rosenbloom RG, Tinanoff N. Salivary Streptococcus mutans levels in patients before, during, and after orthodontic treatment. Am J Orthod Dentofacial Orthop. 1991 Jul;100(1):35-7.

39. Sakamaki ST, Bahn AN. Effect of orthodontic banding on localized oral lactobacilli. J Dent Res. 1968 Mar-Apr;47(2):275-9.

40. Samra Z, Bahar J, Madar-Shapiro L, Aziz N, Israel S, Bishara J. Evaluation of CHROMagar KPC for rapid detection of carbapenem-resistant Enterobacteriaceae. J Clin Microbiol. 2008 Sep;46(9):3110-1.

41. Sreenivasan PK, Mattai J, Nabi N, Xu T, Gaffar A. A simple approach to examine early oral microbial biofilm formation and the effects of treatments. Oral Microbiol Immunol. 2004 Oct;19(5):297-302.

42. Steinberg D, Eyal S. Initial biofilm formation of Streptococcus sobrinus on various orthodontics appliances J Oral Rehabil. 2004 Nov;31(11):1041-5

43. Sukontapatipark W, el-Agroudi MA, Selliseth NJ, Thunold K, Selvig KA. Bacterial colonization associated with fixed orthodontic appliances. A scanning electron microscopy study. Eur J Orthod. 2001 Oct;23(5):475-84

44. Takada K, Hirasawa M. A novel selective medium for isolation of Streptococcus mutans. J Microbiol Methods. 2005 Feb;60(2):189-93.

45. Wan AK, Seow WK, Purdie DM, Bird PS, Walsh LJ, Tudehope DI. A longitudinal study of Streptococcus mutans colonization in infants after tooth eruption. J Dent Res. 2003 Jul;82(7):504-8.

46. Wan AK, Seow WK, Walsh LJ, Bird PS. Comparison of five selective media for the growth and enumeration of Streptococcus mutans. Aust Dent J. 2002 Mar:47(1):21-6.

47. Wicht MJ, Haak R, Kneist $\mathrm{S}$, Noack MJ. A triclosan-containing compomer reduces Lactobacillus spp. predominant in advanced carious lesions. Dent Mater. 2005 Sep;21(9):831-6 